\title{
Representações sociais de avaliação processual construídas por professoras
}

Gleice Kelly de Souza Guerra* Laêda Bezerra Machado**

\section{Resumo}

Este artigo analisa as representações sociais de avaliação processual construidas por professoras dos anos iniciais do Ensino Fundamental da Rede Municipal da cidade do Recife-PE. 0 referencial de base para o estudo foi a Teoria das Representações Sociais de Moscovici $(1978,2003)$ e Jodelet (2001). 0 estudo foi realizado junto a 20 docentes. A entrevista semiestruturada foi utilizada como procedimento de coleta. Tratamos o material com o suporte da Análise de Conteúdo. Os resultados apontam a existência de uma representação social que ganha contornos em função do uso diversificado de instrumentos avaliativos de modo a resgatar uma memória significativa das aprendizagens dos alunos. Esse conhecimento, entretanto, parece está sendo usado pelas professoras de forma difusa e pouco consistente em suas práticas avaliativas. Nossos resultados apontam a necessidade de pesquisas que venham aprofundar esses achados.

Palavras-chave: Avaliação processual. Representações sociais. Professoras.

\section{Social representations of assessment procedures built by teachers Abstract}

This article examines the social representations of assessment procedures built by teachers of early years of Basic Education Network's Hall of the city of Recife-PE. The benchmark as the basis for the study was the Theory of Social Representations Moscovici $(1978,2003)$ and Jodelet (2001). The study was conducted with 20 teachers. The semi-structured interview was used as a procedure for collection. The material was dealt with the support of the

* Mestre em Educação, Universidade Federal de Pernambuco (UFPE). E-mail: gleice.guerra@ig.com.br

** Doutora em Educação, UFPE; Professora, Programa de Pós-Graduação em Educação, UFPE. E-mail: laeda@oi.com.br 
Analysis of Content. The results indicate the existence of a social representation that is being carried out by the teachers with diverse evaluation instruments in order to recover a significant memory of learning of students. This knowledge, however, is being used by teachers in a diffuse and less consistent way in their evaluation practices. Our results suggest the need for research that will examine these findings mores carefully.

Keywords: Assessment procedures. Social representations. Teachers.

\section{Representaciones sociales de evaluación procesual construidas por profesoras Resumen}

Este artículo analiza las representaciones sociales de evaluación procesual que profesoras de los años básicos de la Primaria de la Red Municipal de la ciudad de Recife (PE-Pernambuco-Brasil) construyeron. El punto de referencia básico para el estudio fue la Teoría de las Representaciones Sociales de Moscovici (1978; 2003) y Jodelet (2001). El estudio se realizó con 20 profesores. La entrevista semiestructurada se utilizó como un procedimiento para la recolección. Se trató el material con el apoyo del Análisis de Contenido. Los resultados señalan la existencia de una representación social que se perfila en función del uso diversificado de instrumentos de evaluación con el objeto de rescatar una memoria significativa del aprendizaje de los alumnos. Parece, sin embargo, que las profesoras usan ese conocimiento de forma difusa y poco consistente en sus prácticas de evaluación. Nuestros resultados señalan la necesidad de investigaciones que profundicen más estas conclusiones.

Palabras clave: Evaluación procesual. Representaciones Sociales. Profesoras.

\section{Introdução}

A história da educação brasileira mostra que, durante certo tempo, o termo avaliar foi usado como sinônimo de medida ficando, portanto, a avaliação escolar reduzida à classificação e à promoção do educando. A partir da década de 1970, 0 conhecimento construído na área educacional passa a ser marcado por uma base psicologizante que reduzia a compreensão do social às influências de contexto e de relações intergrupais. Assim, embora a preocupação com a aprendizagem ainda incidisse sob os resultados finais, o modelo de avaliação presente deslocava a centralidade das habilidades dos alunos para o julgamento do currículo. Na segunda metade da década de 1980, o paradigma avaliativo de orientação comportamental é alvo de questionamentos de estudiosos internacionais (PERRENOUD, 1999, 2004; MÉNDEZ, 2002) e nacionais (ESTEBAN, 1999, 2005; SILVA, 2003, 2004; HOFFMANN, 2001, 2003, 2005; LUCKESI, 2005) que passaram a redefinir o processo avaliativo numa direção includente. 
Desde aquele periodo, em diferentes vertentes, vários estudiosos têm se empenhado em buscar novos caminhos à prática avaliativa à medida que a avaliação passou a ser substituída por um processo contínuo cuja função é retroalimentar a aprendizagem do aluno e a prática docente. Na década de 1990, esse conhecimento repercutiu nas políticas educacionais para o Ensino Fundamental, a exemplo dos Parâmetros Curriculares Nacionais e as políticas de ciclos visto que passaram a apresentar orientações contrárias à perspectiva tradicional do avaliar. Nesse contexto de mudanças, os profissionais da educação foram levados a repensar suas práticas em função desses novos paradigmas, pois a avaliação escolar passou a ser encarada como um processo diário, contínuo e integrador da ação educativa, devendo respeitar o educando no seu processo de aprendizagem, ritmo e estágio de desenvolvimento.

Este artigo tem como objetivo analisar as representações sociais de avaliação processual ${ }^{1}$ construídas por professoras dos anos iniciais do Ensino Fundamental da Rede Municipal da cidade do Recife-PE. Mesmo admitindo o crescente número de pesquisas já realizadas acerca das práticas avaliativas (LUIS, 2000; ESTEBAN, 2002; KNOBLAUCH, 2004; CUNHA, 2005; BATISTA, 2006; GOMES, 2006; VILLAS BOAS, 2007; PORTUGAL, 2008), permanecem escassas as produções divulgadas no Brasil quando se trata de orientações focadas na perspectiva teórico-metodológica das representações sociais. Localizamos a pesquisa de Candido e Batista (2007) que, por meio de uma abordagem cognitivo-estrutural, buscara conhecer o modo como alunos das redes públicas de Cuiabá eram avaliados por seus professores; bem como o estudo de Alves e Madeira (2007) que, aliando a perspectiva cognitivo-estrutural à abordagem processual, analisara as representações sociais de avaliação que circulam entre professores de Ensino Fundamental da Rede Pública Municipal de Duque de Caxias, RJ.

Frente à escassez de trabalhos que se propõem a abordar o universo das representações sociais construídas por professores em torno da experiência vivida no processo de avaliação, podemos reafirmar a relevância de nosso estudo. Isso porque, além de trazer à tona a discussão de uma atividade constante nas práticas dos professores - a avaliação escolar -, busca investigar, a partir da Teoria das Representações Sociais, como proposta por Serge Moscovici (1978), como a avaliação processual é significada e vivida pelas professoras. Essa teoria, além de reconhecer o senso comum como um saber que possui valor explicativo sobre a realidade, confirma sua capacidade de orientar as práticas cotidianas. A Teoria das Representações Sociais desdobra-se em três correntes complementares. Este artigo toma como suporte as proposições de Moscovici com ênfase nas produções de Denise Jodelet (2001), porque, além de ser a abordagem mais próxima do constructo original, está pautada em uma orientação de base etnográfica que se assenta em ampla base descritiva dos fenômenos de representação tendo em vista compreender seus processos de produção e sua dinâmica social.

1 Utilizamos a expressão “avaliação processual” ou "avaliação como processo" para configurar nosso objeto de estudo já que as docentes recorriam a essa expressão para caracterizar suas práticas avaliativas. 


\section{A teoria das representações sociais: proposições básicas}

A Teoria das Representações Sociais, criada pelo psicólogo social francês Serge Moscovici nos anos 50, caracteriza-se como um campo de estudos sobre o fenômeno de apropriação do conhecimento pelo senso comum. 0 fenômeno das representações sociais e a teoria que se ergue para explicá-lo diz respeito à construção de saberes mediante inumeráveis episódios cotidianos da interação social. Moscovici (1978) estabelece, em verdade, uma nova postura epistemológica ao afirmar que a absorção da ciência pelo senso comum não é, como geralmente se defendia, uma mera reprodução do campo científico, mas sim, reelaborada de acordo com a própria conveniência e os meios e materiais encontrados. Isto é, trata-se de um tipo de conhecimento adaptado a outras necessidades e que obedece a contextos específicos onde cada sujeito aprende à sua maneira a elaborar os conhecimentos científicos fora de espaço em que foram gerados, imbuindo-se do conteúdo e do estilo de pensamento que lhes representam.

Um primeiro delineamento formal do conceito e da Teoria das Representações Sociais surgiu por ocasião dos estudos de Moscovici (1978) sobre a psicanálise que foi apresentada em sua obra clássica: "La psycanalise: son image et son public", no ano de 1961. De caráter plurimetodológico, o trabalho inaugural deste autor coletou algumas das representações sociais vigentes na França sobre a psicanálise. Sá (1995) evidencia que Moscovici, ao tentar compreender como a psicanálise se inseriu na sociedade francesa, não pretendia apenas criar e consolidar um novo campo de estudos, mas, buscava, também, redefinir os conceitos da psicologia social devido à perspectiva individualista que se instalara nesta disciplina no início do século passado. É, pois, em função da insatisfação com a tradição norte-americana dominante que se encontrava fortemente influenciada por uma visão comportamental e cognitivista, que Moscovici, pontua Sá (1998), passa a integrar uma psicologia de origem europeia, para a qual a realidade é reconstruída a partir das relações estabelecidas com o meio social.

Sá (1995) pontua, entretanto, que para fazer frente ao excessivo individualismo que se instalara na psicologia norte-americana, Moscovici foi buscar uma primeira contrapartida conceitual no conceito de "representações coletivas" da sociologia de Durkheim, para quem as tentativas de explicar, psicologicamente, os fatos sociais se constituiam um erro grotesco. Embora impulsionado pelas ideias durkheinianas, Moscovici se afasta destas, pois, contrariamente a esta vertente para quem o sentido das ações sociais não pode ser investigado a partir das intenções ou motivações dos agentes que as realizam, Moscovici estabelece um modelo teórico de compreensão da realidade que abandona a distinção clássica entre sujeito e objeto. De acordo com Guareschi e Jovchelovith (1995, p. 19), a Teoria das Representações Sociais "centra seu olhar sobre a relação entre os dois. Ao fazer isso, ela recupera um sujeito que, através de sua atividade e relação com o objeto-mundo, constrói tanto o mundo como a si próprio". 
A Teoria das Representações Sociais, conforme enfatiza Alves-Mazzotti (2000), procura, pois, dialetizar as relações entre individuo e sociedade, afastando-se igualmente da visão sociologizante de Durkheim e da perspectiva psicologizante da Psicologia Social, então hegemônica. Orientada pela hipótese da existência de diferentes universos de significados atrelados aos distintos grupos, classes ou culturas, a psicologia social em que Moscovici (1978) se insere leva a outras exigências originais que veem se atenuando no emprego da Teoria das Representações Sociais, quais sejam, às dimensões das representações e seus processos formadores. Em relação à primeira, Moscovici (1978) postula que uma representação social se configura a partir de três dimensões articuladas, a saber: a informação, campo de representação ou imagem e atitude. Segundo o autor, a dimensão da informação encontra-se relacionada à organização dos conhecimentos que um conjunto social possui a respeito de um dado objeto. 0 campo de representação ou imagem diz respeito ao conteúdo concreto e limitado das proposições concernentes a um aspecto preciso do objeto da representação. A atitude é a dimensão que destaca a orientação global em relação ao objeto de representação social.

A segunda exigência refere-se a dois processos cognitivos, dialeticamente relacionados, que atuam na formação das representações: a ancoragem e a objetivação. Segundo Moscovici (1978, p. 61), a ancoragem consiste em um processo em que alguns elementos desconhecidos são introduzidos em nosso sistema particular de categorias na tentativa de tornar familiar o insólito e insólito o familiar e, com isso, "atenuar essas estranhezas e introduzi-las no espaço comum, provocando o encontro de visões, de expressões separadas e dispares que, num certo sentido, se procuram". A objetivação, por sua vez, consiste em transformar conceitos e concepções em coisas concretas e materiais que constituem a realidade. Isto é, "[...] reabsorver um excesso de significações materializando-as [...]. E também transplantar para o nível da observação o que era apenas inferência ou símbolo" (MOSCOVICl, 1978, p. 111). É válido dizer que os mecanismos geradores das representações sociais são também alvo de discussão em outro estudo (MOSCOVICl, 2003, p. 61) no qual o autor os detalha da seguinte forma:

0 primeiro mecanismo tenta ancorar ideias estranhas, reduzilas a categorias e a imagens comuns, colocá-las em um contexto familiar. [...] 0 objetivo do segundo mecanismo é objetivá-los, isto é, transformar algo abstrato em algo quase concreto, transferir o que está na mente em algo que exista no mundo físico. [...] Esses mecanismos transformam o não-familiar em familiar, primeiramente transferindo-o a nossa própria esfera particular, onde nós somos capazes de compará-lo e interpretá-lo; e depois, reproduzindo-o entre as coisas que nós podemos ver e tocar, e, conseqüentemente, controlar.

Ao ressaltar a visão de indivíduo ativo, participativo e criativo na sociedade contemporânea, a Teoria de Moscovici (1978) tem sido endossada por diversos autores chegan- 
do, inclusive, a se desdobrar, hoje, em três correntes complementares: uma liderada Willem Doise, que enfoca os objetos de representação social em uma perspectiva mais sociológica; outra por Jean-Claude Abric, que enfatiza uma dimensão cognitiva estrutural das representações; e uma terceira por Denise Jodelet (2001), que vem se dedicando a precisar e sistematizar a evolução do conceito de representação social (SÁ, 1998). Para o autor, uma das grandes contribuições da autora diz respeito a sua ênfase à consideração dos suportes pelos quais as representações são veiculadas na vida cotidiana. Ela chama atenção, ainda, acerca das condições de produção e circulação das representações sociais, ou seja, são sempre de alguma coisa, sustentadas por alguém. Seria, então, imprescindivel identificar o grupo que as veicula, situar seu conteúdo simbólico no espaço e tempo, e relacioná-lo funcionalmente a um contexto específico.

Sob essa ótica, Jodelet (2001) afirma que as representações sociais são criadas porque sempre há necessidade de estarmos informados sobre o mundo que nos cerca de modo que possamos nos ajustar a ele, identificando e resolvendo os problemas que se apresentam. Assim, a autora assinala que a representação social é uma forma de conhecimento socialmente elaborado, com um objetivo prático, e que, portanto, contribui para a construção de uma realidade comum a um conjunto social. Qualificar esse saber de prático, sublinha a autora, refere-se "à experiência a partir da qual ele é produzido, aos contextos e condições em que ele o é e, sobretudo, ao fato de que a representação serve para agir sobre o mundo e o outro, o que desemboca em suas funções e eficácias sociais" (JODELET, 2001, p. 48). Assim sendo, as representações sociais, enquanto sistemas de interpretação que regem as relações das pessoas com 0 mundo e com os outros, orientam e organizam as condutas e comunicações sociais.

\section{Metodologia}

Fundamentada na Teoria das Representações Sociais, a abordagem metodológica aqui adotada é de natureza qualitativa. Conforme Spink (1995), essa teoria tem por objetivo entender a construção da realidade na interface entre explicações cognitivas, investimentos afetivos e demandas concretas derivadas das ações do cotidiano. É, pois, partindo do entendimento de que as representações sociais se encontram ligadas, enquanto fenômenos psicológicos e cognitivos, à dinâmica e a energética das interações sociais, que buscamos compreender as nuanças, os sentidos e os significados atribuídos à avaliação processual pelas professoras alvo deste estudo.

\section{Procedimento de coleta de informações: a entrevista semiestruturada}

0 cotidiano das práticas avaliativas foi estudado mediante o uso de entrevistas semiestruturadas. Esse procedimento, de caráter interacional e flexível, apresentase como uma ferramenta indispensável porque tem sido amplamente privilegiado entre pesquisadores que estudam as representações sociais a exemplo de Jodelet, 
existindo um consenso entre os seguidores da Teoria das Representações Sociais acerca do seu papel fundamental no levantamento do conteúdo das representações. Além disso, sua utilização é propícia porque, como admite Moscovici (1995), nas conversações também são veiculados valores que permitem ao pesquisador aproximar-se mais dos objetos simbólicos, como as representações sociais. Na tentativa de garantir uma aproximação dos sentidos atribuídos à avaliação processual, buscamos com base em um roteiro caracterizar as professoras quanto a variáveis como idade, formação acadêmica, tempo de profissão e, em seguida, explorar elementos simbólicos referentes à prática avaliativa.

\section{Campo empírico}

O campo empírico contemplou instituições escolares da rede municipal da cidade do Recife-PE, que desde 2001 implementou o sistema de ciclos de aprendizagem em substituição da organização seriada do Ensino Fundamental. A escolha deste campo deveu-se ao fato da referida rede vir suscitando uma maior discussão e revisão das tendências dominantes de avaliação no intuito de institui-la como instrumento de auto-regulação do processo educativo. A escolha obedeceu também ao critério de ter sido nesses espaços presenciados, apesar da proposta inovadora, práticas avaliativas que se limitavam ao julgamento de resultados do desempenho dos alunos.

\section{Participantes}

Participaram do estudo 20 professoras $^{2}$ que lecionavam nos anos iniciais do Ensino Fundamental. Privilegiamos as docentes graduadas em Pedagogia que tinham iniciado a formação acadêmica na década de $1990^{3}$. Pautamos-nos na premissa de que as professoras formadas naquele período apresentariam uma formação acadêmica mais atualizada e coerente com as tendências atuais do avaliar. Isto é, o conhecimento construído sobre avaliação Ihes daria suporte para uma atuação voltada à regulação contínua das aprendizagens dos alunos. A escolha do grupo também se deveu ao fato de ser no início da escolarização que a avaliação exerce presença marcante e, muitas vezes, decisiva no engajamento, ou não, dos alunos em seu contexto social mais amplo.

De modo geral, no grupo de professoras entrevistadas, embora haja uma variação do nivel de formação, a maioria, oito delas, possui pós-graduação lato sensu concluída. Treze das docentes concluíram a graduação na Universidade Federal de Pernambuco/ UFPE. A maior parte, 11 delas, se formou entre os anos de 2004 e 2008.0 tempo de serviço do grupo oscilou entre um e 35 anos. É válido mencionar que 14 delas mantêm vínculo profissional com outros municípios da Região Metropolitana como Olinda e

2 Embora não tenhamos delineado para a composição da amostra sujeitos participantes que fossem apenas do sexo feminino, nos deparamos, no contato com o campo empírico, com esse grupo e, portanto, em virtude dessa constatação redefinimos esta variável na composição da amostra.

3 Para mapeamento das participantes, fizemos uso de um estudo exploratório que, a partir de elementos relacionados à formação acadêmica e atuação profissional, localizou na rede o grupo de professoras. 
Jaboatão dos Guararapes. Em relação às turmas que lecionavam, a maioria, 15 das docentes, atuava em turmas de $1^{\circ}$ ciclo do Ensino Fundamental. A faixa etária do grupo é diversificada, mas a maioria, seis delas, tem de 31 a 35 anos de idade 4 .

\section{Procedimento de coleta}

0 trabalho de campo foi realizado entre 1 a 19 de setembro de 2008 e envolveu 14 escolas municipais. Todas as professoras se disponibilizaram a participar das entrevistas que foram gravadas em áudio e transcritas logo depois de encerrada cada uma delas. As informações emitidas pelo grupo foram guiadas por um roteiro que partiu de questões relacionadas às experiências cotidianas para, gradativamente, passar a perguntas que envolviam reflexões mais abstratas e de julgamentos. Os locais disponíveis para a realização das entrevistas foram os mais diversos possiveis: sala dos professores, sala de aula, biblioteca, direção e pátio das escolas. De modo geral, as professoras demonstraram se sentir à vontade para se expressar frente aos questionamentos propostos e, em função da dinâmica que permeou o momento das entrevistas, sua duração foi bastante variada oscilando entre vinte minutos à uma hora.

\section{Procedimento de análise}

Para o tratamento dos dados das entrevistas semiestruturadas utilizamos a análise de conteúdo de Bardin (2004). Em termos práticos, três fases são especificadas no trabalho com essa técnica, quais sejam: pré-análise, exploração do material e interpretação inferencial. Na primeira fase, busca-se a partir de uma leitura flutuante estabelecer contato exaustivo com o material coletado. Na segunda fase, submete -se o corpus colhido a um conjunto de procedimentos como os de codificação, classificação e categorização. Na terceira fase, inicia-se um processo minucioso de interpretação que visa a ultrapassar o alcance meramente descritivo do conteúdo manifesto da mensagem, para descobrir, mediante a inferência, seu sentido velado. É válido pontuar que, para analisar o conteúdo expresso pelas entrevistas, trabalhamos com o tema enquanto unidade de registro. Esta unidade de significação, além de ser uma das mais utilizadas, possibilita ao pesquisador colocar em relevo os "núcleos de sentido" que compõem uma comunicação cuja presença ou frequência de aparição tende a se apresentar como definitória do caráter do discurso manifesto pelos atores sociais.

\section{Resultados e discussão}

A partir das impressões que o grupo de professoras entrevistadas teceu sobre suas práticas avaliativas, estabelecemos uma aproximação das representações sociais de avaliação processual visto que elas são fenômenos simbólicos socialmente

4 As professoras serão identificadas pela letra inicial de professor "P", seguida do número do protocolo das entrevistas aplicadas a essas profissionais e das iniciais referentes à sua formação acadêmica, no caso, "PG” (Pós-Graduação), “CPG” (Cursando Pós-Graduação) e “G” (Graduação). Assim, por exemplo, (P15PG) significa professora de protocolo número 15 cujo nivel de formação é Pós-Graduação. 
elaborados. Para tanto, trabalhamos a partir de três categorias empíricas, a saber: a) Sentidos atribuídos à avaliação processual; b) Instrumentos avaliativos utilizados em sala de aula; e, por fim, c) Práticas de correção tecidas na dinâmica do processo avaliativo. Essas categorias, embora estejam didaticamente separadas, foram construidas a título de sistematização e, portanto, são interdependentes. Apesar disso, nos limites deste artigo, discutiremos apenas a segunda delas aqui apresentada.

\section{Instrumentos avaliativos utilizados em sala de aula}

0 ato de avaliar é uma ação que exige do professor o uso diversificado de instrumentos avaliativos de forma a ser possivel resgatar uma memória significativa do percurso de aquisição do conhecimento pelos educandos tendo em vista a diversidade em seus níveis de aprendizagem. Devido ao fato de a avaliação escolar vir assumindo uma característica dinâmica no processo educativo por meio do qual o professor deverá diversificar, tanto quanto possivel, os instrumentos de avaliação para obter dados relevantes sobre o desempenho dos alunos, as professoras entrevistadas afirmaram, de modo geral, que faziam a avaliação de suas turmas diariamente, observando a elaboração de suas atividades. Desta forma, a maioria delas afirmou que os instrumentos utilizados para avaliar os alunos eram as atividades de sala frente às quais algumas especificaram sua natureza (leitura, ditado, produção de texto, seminário, trabalho individual e de grupo), seguidas da participação, provas/testes, observações e tarefa de casa.

Apesar de o grupo de professoras entrevistadas ter apontado a necessidade de se fazer uso dos mais variados instrumentos de avaliação para acompanhar cada aluno, em sua expressão única e singular do conhecimento, a maioria delas afirmou utilizar, periodicamente, a prova para uma avaliação mais formal. Outras, entretanto, pontuaram, de modo genérico, que utilizavam certas atividades para uma avaliação mais formal, mas não as denominaram de provas. Assim, quando indagadas sobre o porquê de recorrerem às provas escritas ou a atividades semelhantes às trabalhadas no dia a dia para estarem realizando com certa periodicidade uma avaliação mais formal de seus alunos, as professoras elencaram os seguintes aspectos: verificação de conhecimentos; verificação de conhecimentos e exigências sociais; verificação de conhecimentos e cobrança dos pais; cobrança dos pais e autonomia dos alunos.

0 primeiro aspecto apontado pelas professoras acima aludidas para a realização de uma avaliação mais formal dos alunos, "verificação de conhecimentos", refere-se à necessidade que as mesmas têm de obter informações acerca das aprendizagens efetivadas durante determinado intervalo de tempo. Ou seja, o grupo de professoras aplica periodicamente provas ou atividades semelhantes para acompanhar regularmente se os objetivos estão sendo atingidos pelos educandos. Nessa perspectiva, insistem na utilidade desses instrumentos avaliativos: "[...] quando eu vejo o nível dos meninos aí, automaticamente, eu já vou vendo o domínio do conteúdo das outras disciplinas e tem ajudado bastante" (P08CPG); "Você com aquele material 
escrito vai facilitar pra você lembrar como é que tá aquele aluno de ver em que, em que momento ele tá do processo de aprendizagem dele" (P15PG). Essa premissa é corroborada por outras professoras, como explicita o depoimento:

[...] a avaliação é feita diária nas atividades que são feitas em sala de aula e nas atividades que eles levam pra fazer em casa, mais, mais em sala de aula porque aqui a gente tá presente e tá vendo que realmente ele tá desenvolvendo, ou não, aquela competência que ele adquiriu. Mas, quando chega, assim [...], término do primeiro semestre aí a gente, $\mathrm{eu}$, particularmente, eu costumo fazer uns exercícios isolados, individuais pra testar o que foi que ele adquiriu do começo do ano até as, o recesso de julho e no final do ano pra vê o que ele adquiriu de julho até dezembro [...] (P11G).

0 entendimento do grupo professoras entrevistadas sobre a finalidade das provas/ testes ou atividades semelhantes trabalhadas em sala de aula constitui-se, para maioria delas, numa espécie de inventário acerca dos conhecimentos construídos pelos alunos com o objetivo de pôr à prova, de verificar resultados alcançados, conforme preconiza Tyler (1974). Tal fato aponta, portanto, para uma aproximação com uma prática avaliativa pautada nos pressupostos das abordagens mais tradicionais, já que 0 grupo de professoras também não deu indicativos de sua importância para reorientar o ensino. Em outros termos, não explicitaram a preocupação em acompanhar, através do instrumento avaliativo referendado, os percursos dos educandos na sua trajetória de construção do conhecimento como condição para dinamizar, se necessário, novas oportunidades de o aluno refletir sobre os conteúdos já trabalhados.

0 segundo aspecto destacado, "verificação de conhecimentos e exigências sociais", refere-se à obtenção de informações acerca das aprendizagens dos alunos tendo em vista os objetivos pré-estabelecidos, bem como ao fato de que avaliar através de provas se constitui numa ação necessária e relevante para atender às exigências de avaliações institucionais ${ }^{5}$ como a Provinha Brasil, o Sistema de Avaliação da Educação Básica (SAEB) e exames a exemplo dos vestibulares e, com isso, evitar o fracasso e as inúmeras consequências deles sobre todos. Essa função atribuída às situações denominadas de prova foi evidenciada em algumas falas, conforme mostra o estrato: "[...] quer queira, quer não, o mundo lá fora requer provas, eles vão ter que ser avaliados por meio de provas. Eles vão ter que se acostumar, se

50 Ministério da Educação, por meio do Instituto Nacional de Estudos e Pesquisas Educacionais Anísio Teixeira (Inep), elaborou um conjunto de instrumentos avaliativos, a exemplo da Provinha Brasil e o (SAEB), para gerir informações sobre a realidade educacional. A Provinha Brasil permite identificar o desempenho de alunos em processo de alfabetização no $2^{\circ}$ ano de escolaridade do Ensino Fundamental. Já o SAEB avalia os alunos matriculados nos últimos anos do Ensino Fundamental. Os exames de vestibulares, em contrapartida, aferem os conhecimentos adquiridos no Ensino Fundamental e Médio sendo o principal meio de acesso ao ensino superior no Brasil.

Ensaio: aval. pol. públ. Educ., Rio de Janeiro, v. 19, n. 71, p. 363-380, abr./jun. 2011 
adequar a isso [...]" (P02G). Outra evidência de que implementação do processo de avaliação institucional vem exercendo um forte controle no trabalho docente pode ser observada na passagem abaixo em que uma das professoras questiona:

[...] Me diga o que é o vestibular? [...] Meu aluno sai daqui vai
se submeter a um vestibular, o vestibular não vai cobrar dele o
menor centésimo em nota? Não vai cobrar dele, não vai ser
feito de uma forma é [...], de exercícios? De nota? De prova? Ele
não vai ter que se submeter a ela? Porque a vida vai cobrar dos
meus alunos testes, provas e eu acho injusto que eu não pre-
pare ele pra isso. [...] Aqui a gente combinou, assim, olha: a
gente faz, a gente ver o aluno, a gente observa, a gente olha os
cadernos, olha os exercícios, olha a interpretação que a gente
faz é [...] oral, mas a gente também faz um teste por conta que
a vida vai cobrar isso dele e ele tem que tá preparado, né? E a
gente não tá preparando ele só para município, só pra sala de
aula, a gente prepara o aluno da gente pra vida [...] (P19G).

Para Esteban (2005), o encaminhamento da uma prática avaliativa, tomado nessa direção, reduz, muitas vezes, a riqueza e a complexidade dos processos de ensino e aprendizagem. Isso porque a ênfase do processo avaliativo passa a ser posta nos resultados alcançados e na possibilidade de sua quantificação sendo os alunos, desta forma, submetidos, ainda que inconscientemente, a um massacre propedêutico. Apesar de as professoras buscarem atender às exigências postas pelas avaliações externas, elas enfatizam que, ao fazer uso desse instrumental, sempre procuram viabilizar a concretização de uma prática que valorize as aprendizagens anteriores dos alunos a fim de que elas sirvam como base para a construção de novos saberes. A respeito do papel das práticas cotidianas escolares na construção das representações sociais Gilly (2001p. 337), é esclarecedor quando, com base nos resultados de diversos trabalhos junto a diferentes grupos populacionais relacionados à instituição escolar, afirma:

as representações sociais, enquanto sistemas autônomos de significações sociais, são o produto de compromissos contraditórios sob a dupla pressão de fatores ideológicos e de imposições relacionadas ao funcionamento efetivo do sistema escolar. 0 peso destas últimas parece ainda mais forte, tendo em vista que os indivíduos são diretamente afetados pelas - ou implicados nas - práticas cotidianas.

0 terceiro aspecto abordado, "verificação de conhecimentos e cobrança dos pais", envolve a constatação das aprendizagens conquistadas pelos alunos e a necessidade social de prestação de contas à familia das crianças. Assim, as docentes, além de buscarem constatar o desempenho dos alunos, atribuíram à cobrança que os pais fazem acerca da prova/testes ou certas atividades semelhantes a razão para 
estarem realizando avaliações mais formais. Nesse sentido, uma delas afirma: "[...] a prova é só mesmo, eu acho, para mostrar aos pais e pra você vê como é que eles [os alunos] tão se comportando em uma situação prática, né? [...]" (P05G); Uma outra professora destaca: "Eu acho que vai servir muito pra isso, não só pra mim que tô no processo de ensino [...], mas pros próprios pais que, às vezes, não olham todas as atividades, não olham todos os cadernos, nem os livros em casa, mas se pegar uma avaliação do semestre vai identificar realmente se ele [o aluno] avançou ou não avançou" (P10G). Outro trecho de fala reforça essa justificativa das professoras:

Eu ainda faço, assim, umas avaliações até pra uma satisfação pros pais porque pela cultura deles, eles acham, não acham... eles não acreditam que se não fizer prova a gente tá acompanhando, eles não acreditam. Mesmo que, assim, todas as tarefinhas que eles fazem eu junto, depois em mando mesmo, assim, eles não acreditam. Então, agora mesmo eu tô botando aquela provinha convencional, eu mostro a eles depois que termina porque a gente tem que mostrar porque aí eles ficam satisfeitos, mas, ainda tem os que cobram ainda nota, né? Aí eu coloco assim: muito bem! Bom! Razoável! Precisa melhorar! Converso com o pai, falo, entendeu? [...] (P14CPG).

A partir das falas acima descritas, podemos afirmar que, embora as professoras não neguem a confiabilidade de outros instrumentos para avaliar os alunos, conforme já evidenciamos, consideram ser a prova o instrumento de "prestígio social" que possibilita verificar de forma mais concreta a capacidade de expressão do conhecimento dos alunos. Mostram, ainda, que os pais se mantêm resistentes às posturas mais avançadas de avaliação e que a prova ainda se apresenta para eles como um "porto seguro" que comprova tanto as aprendizagens consolidadas pelos alunos, quanto 0 comprometimento do professor com o processo educativo. Nessa perspectiva, podemos depreender que a prova quase nunca é questionada, pois além de supostamente comprovar com eficiência resultados finais funcionam "como redes de segurança em termos de controle exercido pelos professores sobre seus alunos, das escolas e dos pais sobre os professores, do sistema sobre suas escolas" (HOFFMANN, 2003, p. 22).

Corroborando com as nossas discussões, estudos como os de Batista (2006) e Portugal (2007) mostram que para os professores a garantia de vir avaliando as aprendizagens da melhor forma se encontra atrelada à prova como instrumento avaliativo. Os resultados deixam entrever, ainda, que o prestígio social atribuído a esse instrumento pelo grupo se encontra relacionado não apenas às suas representações sociais de prova, mas também à pressão social exercida pelos pais na organização do trabalho docente. Assim, é pertinente chamar atenção para a prática de aplicar e coletar tarefas avaliativas como forma de apenas mostrar aos pais ou cumprir uma exigência burocrática, pois caso o professor não analise o sentido 
atribuido aos instrumentos que elabora, eles serviram apenas para "notificar o aprendente, supostamente quantificar as suas respostas e posicioná-lo numa 'hierarquia de excelência'" (SILVA, 2004, p. 69).

0 quarto aspecto destacado pelo grupo de professoras, "cobrança dos pais e autonomia", diz respeito à necessidade de dar retorno aos pais das aprendizagens efetivadas pelos alunos e, também, de observar o que o educando é capaz de fazer de forma autônoma, sem intervenção do professor e colaboração de seus pares. $\dot{E}$ válido salientar que do grupo de professoras entrevistadas uma delas destacou apenas a "autonomia" como elemento justificador para estar aplicando provas juntamente aos alunos. Isto é, afirmou avaliar seus alunos com o intuito de verificar quais saberes estavam consolidados em suas estruturas cognitivas a partir do que 0 aluno consegue fazer sozinho. A passagem destacada a seguir, mostra de que forma esse aspecto tem perpassado as falas das professoras entrevistadas:

As atividades que eu coloquei foram atividades que eu gostaria que os alunos já estivessem fazendo com autonomia, sozinhos e aí quando você pega e vai dá uma estudada nelas você vai ver que os a..., alguns alunos chegaram nesse nível de ter autonomia, de fazer o nome da escola só, o nome dele só, é..., pelo esquema, né? Que tá a atividade montada ele já sabe que, apesar de não lê, a maioria não lê, mas, já sabe deduzir do que se trata aquela atividade e: tia! Não e assim que faz? É. E você pode ver que tem aluno que tá no nível bem elementar ainda. Eu acho que vai servir muito pra isso [...] (P10G).

Embora a prova seja um instrumento a partir do qual é possivel obter indicativos do grau de autonomia dos alunos, é válido dizer, conforme preconiza Vygotsky (1984), que aquilo que o educando faz com a assistência de outrem é bem mais indicativo de seu desenvolvimento mental do que aquilo que ele consegue fazer de forma independente. Na tentativa de ampliar a reflexão acerca do processo de avaliação, Esteban (1999) recorre ao conceito de "Zona de Desenvolvimento Proximal" introduzido por Vygotsky e diz que, por ser nesse espaço onde os conhecimentos se encontram em construção, deve haver intervenções pertinentes do professor e seus pares de modo que o grupo-classe possa vir a desencadear novas maneiras de pensar e construir os saberes estabelecidos pela aprendizagem. Isso porque, esse conceito:

Ressalta a natureza coletiva, compartilhada e solidária do conhecimento, além da riqueza da heterogeneidade, pois em cooperação os sujeitos revelam seus conhecimentos potenciais, desenvolvem novas potencialidades, articulando um processo permanente de ampliação dos conhecimentos. Forja novos olhares para o movimento de construção de conhecimentos, indica outros caminhos para o pro- 
cesso ensino/aprendizagem, sinalizando uma perspectiva interessante para se repensar a avaliação: o abandono da classificação dos conhecimentos já consolidados, e a busca dos processos emergentes, em construção, que podem anunciar novas possibilidades de aprendizagem e de desenvolvimento (ESTEBAN, 1999, p. 19).

Embora o grupo de professoras tenha justificado de forma diversa o uso das provas escritas ou atividades semelhantes para estarem realizando uma avaliação mais formal, é o uso desse instrumental enquanto verificador de conhecimentos com fins de atingir objetivos prévios que tem se constituído como elemento norteador para sua aplicação. A despeito de todos os avanços, é o apego a essa forma de avaliar que vem se afigurando como o instrumental maior da prática avaliativa. Nesse sentido, podemos depreender que as representações sociais são produtos da comunicação, informação e das experiências acumuladas por um processo histórico dos fatos, cujos elementos constituem o sistema cognitivo das pessoas. Estando, pois, as representações inseridas num contexto de mútuas influências é que Jodelet (2001, p. 26) afirma: "elas devem ser estudadas articulando-se elementos afetivos, mentais e sociais e integrando - ao lado da cognição, da linguagem e da comunicação - a consideração das relações sociais que afetam as representações e a realidade material, social e ideativa sobre a qual elas têm de intervir".

\section{Considerações finais}

0 modo como as professoras se reportaram ao discurso atual, que preconiza o uso diversificado dos instrumentos avaliativos, reforça a ideia de que elas estão se apropriando das discussões que perpassam as novas abordagens do avaliar, a exemplo como se configuraria a avaliação numa perspectiva processual. Entretanto, a afirmação da maioria das professoras de que utilizavam provas ou atividades semelhantes para estarem avaliando periodicamente os alunos dá a impressão, à primeira vista, de que elas compreendiam essa prática como um momento terminal da aprendizagem escolar. Essa impressão é reforçada, ainda, quando elas sinalizaram que o que as fazia realizar as provas era a necessidade de verificar a aprendizagem de determinado conteúdo, sem mostrar preocupação com a retomada dos conteúdos que não foram bem compreendidos. Além disso, avaliar formalmente o aluno para atender exigências dos pais e sociais mais amplas contraria o que está posto como avaliação de caráter processual, tal como nos foi indicado em momentos da entrevista.

Colocando em relevo os usos feitos dos resultados da prova, bem como as decisões e encaminhamentos tomados a partir delas, ousariamos afirmar que esse grupo de professoras parece estar contrariando o sentido de processo inerente à avaliação de bases formativa. Nesse sentido, podemos depreender que as abordagens mais tradicionais do avaliar ainda predominam na estruturação das representações sociais das 
professoras. Isso nos faz pensar que, a despeito das orientações do discurso oficial, midiático, políticas oficiais, formação acadêmica, normatizações educacionais etc., as professoras ainda não imprimiram mudanças em suas práticas avaliativas em grau suficiente para que suas representações de avaliação processual se configurem como um componente que se realiza diariamente, a cada instante na dinâmica escolar.

Esses conflitos e dificuldades, analisados à luz da Teoria das Representações Sociais, nos permitem retomar dois processos destacados por Moscovici (2003) na construção dessas representações: ancoragem e objetivação. Ancorar significa trazer para categorias e imagens conhecidas o que não está ainda classificado e rotulado. A objetivação refere-se ao processo pelo qual se cristaliza uma representação. Através desses processos, podemos dizer que embora as professoras deem indicativos de não fazer uso da prova, tal como acontecia na vigência das abordagens tradicionais e afirmem incorporar outros instrumentos avaliativos em sua práticas, o que observamos é que esse conhecimento parece estar sendo usado de forma difusa e pouco consistente. Isso revela que essas docentes estão vivenciando um processo de ancoragem, pois a teoria e suas implicações pedagógicas acerca do avaliar não chegaram a ser objetivadas por essas profissionais em suas práticas avaliativas.

\section{Referências}

ALVES, M. C. R. P.; MADEIRA, M. C. Representações sociais de professores sobre a avaliação escolar: cenas e cenários a descobrir. In: JORNADA INTERNACIONAL SOBRE REPRESENTAÇÕES SOCIAIS, 5., 2007, Brasília. Trabalhos apresentados... Brasilia, DF, 2007. Disponivel em: <www.vjirs.com.br>. Acesso em: 20 nov. 2007.

ALVES-MAZZOTII, A. J. Representações sociais: desenvolvimentos atuais e aplicações à educação. In: CANDAU, V. M. (Org.). Linguagem, espaços e tempos em ensinar e aprender. Rio de Janeiro: DPSA, 2000.

BARDIN, L. Análise de conteúdo. Lisboa: Edições 70, 2004.

BATISTA, C. 0. A utilização da prova como instrumento de avaliação. In: ENCONTRO NACIONAL DE DIDÁTICA E PRÁTICA DE ENSINO [ENDIPE], 13., 2006, Recife. Anais... Recife, PE, 2006.

CANDIDO, F.; BATISTA, C. M. P. Professores das redes públicas estadual e municipal cuiabanas e suas representações sociais acerca da avaliação. In: JORNADA INTERNACIONAL SOBRE REPRESENTAÇÕES SOCIAIS, 5., 2007, Brasilia. Trabalhos apresentados... Brasilia, DF, 2007. Disponivel em: <www.vjirs.com.br>. Acesso em: 20 nov. 2007. 
CUNHA, E. R. Práticas avaliativas bem-sucedidas de professoras dos ciclos de formação da Escola Cabana de Belém. In: REUNIÃO ANUAL DA ASSOCIAÇÃO NACIONAL DE PÓS-GRADUAÇÃO E PESOUISA EM EDUCAÇÃO [ANPEd], 27., 2005, Caxambu. Trabalhos apresentados... Caxambu, MG, 2005. Disponivel em: <www.anped.org.br>. Acesso em: 20 out. 2007.

ESTEBAN, M. T. A avaliação no cotidiano escolar. In: (Org.). Avaliação: uma prática em busca de novos sentidos. Rio de Janeiro: DPEA, 1999.

A avaliação no processo ensino/aprendizagem: os desafios postos pelas múltiplas faces do cotidiano. In: REUNIÃO ANUAL DA ASSOCIAÇÃO NACIONAL DE PÓS-GRADUAÇÃO E PESQUISA EM EDUCAÇÃO [ANPEd], 24., 2002, Caxambu. Trabalhos apresentados... Caxambu, MG, 2002. Disponivel em:

<www.anped.org.br>. Acesso em: 20 out. 2007.

(Org.). Ser professora: avaliar e ser avaliada. In: . Escola, currículo e avaliação. 2. ed. São Paulo: Cortez, 2005.

GILLY, M. As representações sociais no campo da educação. In: JODELET, D. (Org.). As representações sociais. Rio de Janeiro: EdUERJ, 2001.

GOMES, S. S. Avaliação da aprendizagem na organização escolar em ciclos: concepções, práticas, sentidos e significados atribuídos pelos professores. In: REUNIÃOO ANUAL DA ASSOCIAÇÃO NACIONAL DE PÓS-GRADUAÇÃO E PESQUISA EM EDUCAÇÃO [ANPEd], 28., 2006, Caxambu. Trabalhos apresentados... Caxambu, MG, 2006. Disponivel em: <www.anped.org.br>. Acesso em: 20 out. 2007.

GUARESCHI, P. A.; JOVCHELOVITCH, S. Introdução. In: . (Org.). Textos em representações sociais. 8. ed. Petrópolis: Vozes, 1995.

HOFFMANN, J. Avaliar para promover: as setas do caminho. 7. ed. Porto Alegre: Mediação, 2001.

Avaliação mediadora: uma prática em construção da pré-escola à universidade. 24. ed. Porto Alegre: Mediação, 2003.

Avaliação: mito e desafio: uma perspectiva construtivista. 36 . ed. Porto Alegre: Mediação, 2005.

JODELET, D. Representações sociais um domínio em expansão. In: (Org.). As representações sociais. Rio de Janeiro: EDUERJ, 2001. 
KNOBLAUCH, A. Ciclos de aprendizagem e avaliação de alunos: novas práticas de registro, velhas intenções. In: REUNIÃO ANUAL DA ASSOCIAÇÃO NACIONAL DE PÓS-GRADUAÇÃO E PESQUISA EM EDUCAÇÃO [ANPEd], 26., 2004, Caxambu. Trabalhos apresentados... Caxambu, MG, 2004. Disponivel em: <www.anped.org.br>. Acesso em: 20 out. 2007.

LUCKESI, C. C. Avaliação da aprendizagem escolar: estudos e proposições. 17. ed. São Paulo: Cortez, 2005.

LUIS, S. M. B. Formação docente e avaliação: dos processos formativos ao exercício profissional. 2000. 225 f. Dissertação (Mestrado em Educação) - Centro de Educação, Universidade Federal de Pernambuco, Recife, 2000.

MÉNDEZ, J. M. A. Avaliar para conhecer, examinar para excluir. Tradução de Magda Schwarzhaupt Chaves. Porto Alegre: Artmed, 2002.

MOSCOVICl, S. Prefácio. In: GUARESCHI, P.; JOVCHELOVITCH, S. (Org.). Textos em representações sociais. 2. ed. Petrópolis: Vozes, 1995.

A representação social da psicanálise. Tradução de Álvaro Cabral. Rio de Janeiro: Zahar, 1978.

Representações sociais: investigações em psicologia social. 4. ed. Petrópolis: Vozes, 2003.

PERRENOUD, P. Avaliação: da excelência à regulação das aprendizagens: entre duas lógicas. Porto Alegre. Artmed, 1999. 183p.

PERRENOUD, P. Os ciclos de aprendizagem: um caminho para combater o fracasso escolar. Porto Alegre: Artmed, 2004.

PORTUGAL, J. F. A representação da prova nas práticas avaliativas de professoras das séries iniciais: uma relação de apego e de rejeição. In: ENCONTRO DE PESOUISA EDUCACIONAL DO NORTE E NORDESTE [EPENN], 18., 2007, Maceió. Anais... Maceió, AL, 2007.

Avaliação da aprendizagem e formação docente: as práticas entre 0 dizer e o fazer pedagógico. In: ENCONTRO NACIONAL DE DIDÁTICA E PRÁTICA DE ENSINO [ENDIPE], 13., 2006, Porto Alegre. Anais... Porto Alegre, RS, 2006.

SÁ, C. P. Representações sociais: o conceito e o estado atual da teoria. In: SPINK, M. J. (Org.). $O$ conhecimento no cotidiano: as representações sociais na perspectiva da psicologia social. São Paulo: Brasiliense, 1995. 
SÁ, C. P. A construção do objeto de pesquisa em representações sociais. Rio de Janeiro: EdUERJ, 1998.

SILVA, J. F. Avaliação na perspectiva formativa-reguladora: pressupostos teóricos e práticos. 2. ed. Porto Alegre: Mediação, 2004.

Introdução: avaliação do ensino e da aprendizagem numa perspectiva formativa-reguladora. In: SILVA, J. F.; HOFFMANN, J.; ESTEBAN, M. T. (Org.). Práticas avaliativas e aprendizagens significativas: em diferentes áreas do currículo. Porto Alegre: Mediação, 2003.

SPINK, M. J. Desvelando as teorias implicitas: uma metodologia de análise das representações sociais. In: GUARESCHI, P.; JOVCHELOVITCH, S. (Org.). Textos em representações sociais. Petrópolis: Vozes, 1995.

TYLER, R. W. Princípios básicos de currículo e ensino. Porto Alegre: Globo, 1974.

VILLAS BOAS, B. M. F. A avaliação no bloco inicial de alfabetização no Distrito Federal. In: REUNIÃO ANUAL DA ASSOCIAÇÃO NACIONAL DE PÓS-GRADUAÇÃO E PESQUISA EM EDUCAÇÃO [ANPEd], 29., 2007, Caxambu. Trabalhos apresentados... Caxambu, MG, 2007. Disponivel em: <www.anped.org.br>. Acesso em: 20 out. 2007.

VYGOTSKY, L. S. Interação entre aprendizado e desenvolvimento. In: A formação social da mente. São Paulo: Martins Fontes, 1984.

Recebido em: 10/08/2009

Aceito para publicação em: 10/10/2010 